\title{
Screw-in Atrial Lead in a Sick Sinus Syndrome Patient with Anomalous Inferior Vena Cava
}

\author{
Kuo-Hung LIN,${ }^{1} \mathrm{MD}$, Chi-Tai KuO,${ }^{1} \mathrm{MD}$, and Chih-Ta LIN,${ }^{1} \mathrm{MD}$
}

\begin{abstract}
SUMMARY
Anomalous inferior vena cava without intracardiac anomaly is an unusual condition. Herein, we report a 48-year-old female with left-sided inferior vena cava and azygous continuation, accompanied by sick sinus syndrome. This anomaly resulted in difficulty in implanting a traditional hook-on atrial lead. Atrial lead dislodgment occurred repeatedly soon after implanting the pacemaker because of an anomalous zygous vein draining into the superior vena cava, making a giant connection with the right atrium, thus eliminating the space of the atrial appendage for lead lodgment. Finally, we attempted to utilize a screw-in atrial lead in this patient and she is currently doing well. We therefore suggest that a screw-in atrial lead should be taken into account for such patients in order to obtain a stable fixation. (Jpn Heart J 2001; 42: 639-644)
\end{abstract}

Key words: Screw-in atrial lead, Anomalous inferior vena cava, Sick sinus syndrome

\begin{abstract}
ANOMALOUS inferior vena cava is an unusual malformation with a frequency of about 1.3 percent of all venous malformations. ${ }^{1)}$ This anomaly of the inferior vena cava produces no symptoms by itself. However, it is often associated with some intracardiac anomalies and rhythm disorders. ${ }^{2,3)}$ Herein, we report a patient with an anomalous inferior vena cava and sick sinus syndrome. Difficulties were encountered in implanting a permanent pacemaker probably because of an anomalous venous return. Implantation of an AAIR permanent pacemaker with a traditional hook-on atrial lead was attempted twice but failed both times due to lead dislodgment. The pacemaker was later successfully implanted with a screw-in atrial lead.
\end{abstract}

\section{CASE REPORT}

A 48-year-old female patient was well except for a 10-year history of asymptomatic bradycardia. She was admitted to our hospital for progressive dyspnea, dizziness and near syncope for one month. On admission, her blood pres-

\footnotetext{
From ${ }^{1}$ the First Cardiovascular Division, Department of Medicine, Chang Gung University, and Chang Gung Memorial Hospital-Linkou, Taiwan.

Address for correspondence: Chi-Tai Kuo, MD, Chang Gung Memorial Hospital, 199 Tung-Hwa N Rd., Taipei, Taiwan.

Received for publication December 18, 2000.

Revised and accepted May 14, 2001. 
sure was $122 / 60 \mathrm{mmHg}$ with a regular pulse rate of 35 beats $/ \mathrm{min}$. A grade $2 / 6$ ejection systolic murmur was noted at the aortic area. An electrocardiogram showed marked sinus bradycardia. Holter showed a long sinus pause $>3$ seconds. Chest $\mathrm{x}$-rays revealed a normal heart size with an azygous knob on the right margin of the cardiac silhouette. Asymptomatic sinus bradycardia and sinus pause with junctional rhythm developed during a treadmill exercise test. The echocardiogram failed to show significant abnormalities in the cardiac chambers. During electrophysiologic study, we found the excursion of the catheter in the area of the right atrium was restricted. Venography showed a left-sided inferior vena cava (Figure 1A) draining into an engorged azygous vein in the low thorax region and then into the superior vena cava. Of note, the connection between the superior vena cava and right atrium was dilated (Figure 1B). The right atrial pressure was within normal range. Sinus node recovery time obtained from an overdrive suppression test was prolonged to 4.38 seconds after rapid pacing at a pacing cycle length of $450 \mathrm{msec}$. AV node function was normal. Initially, an AAIR pacemaker with a traditional steroid eluting, tined, hook-on bipolar atrial endocardial lead (CapSure Z 5534-53 cm; Medtronic; Minneapolis, MN) was implanted via the left subclavian approach uneventfully on June 11, 1999 (Figure 2A). However, lead dislodgment was noted soon thereafter when the surgeon was suturing the

A

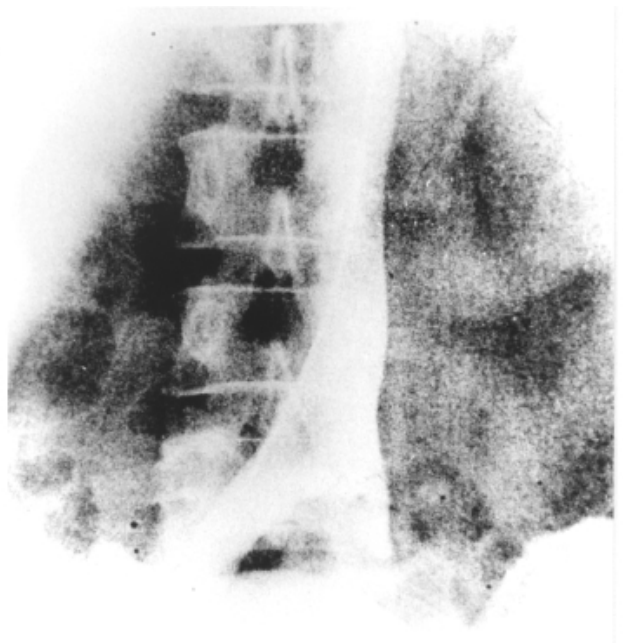

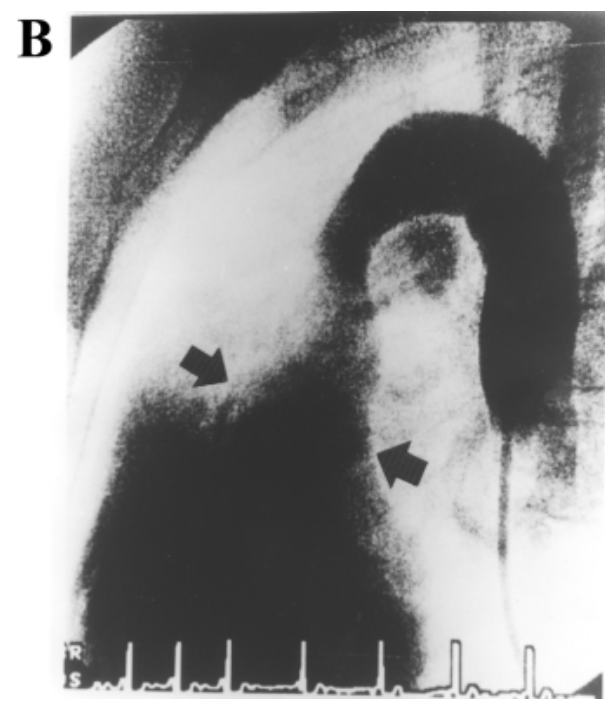

Figure 1 A: Venogram (postero-anterior view) showing a left-sided inferior vena cava. B: Venogram (lateral view) from an enlarged azygous vein showing typical "candy cane" appearance of the anomalous venous pathway. Please note the markedly dilated connection of the superior vena cava and right atrium (between arrows). 
wound. The atrial lead was then re-implanted the same day. The atrial-pacing threshold was $0.6 \mathrm{~V}$, pacing impedance was $844 \mathrm{ohms}$, and $\mathrm{P}$ wave amplitude was $3.2 \mathrm{mV}$ upon initial measurement. A generator was then connected, and the ECG showed normal single-chamber AAIR pacing. Unfortunately, recurrent lead dislodgment was observed the next day. Since the atrial lead dislodged twice, probably because of anomalous azygous vein drainage into the superior vena cava making a giant connection with the right atrium, we decided to use a screw-in atrial lead (CapSureFix 4568-53 cm; Medtronic) for better fixation on June 14, 1999 (Figure 2B). Atrial pacing threshold was $0.8 \mathrm{~V}$, pacing impedance was 412 ohms, and the $\mathrm{P}$ wave amplitude was $2.6 \mathrm{mV}$. Computed tomography of the chest and abdomen showed the viscera in a normal position except for a left-sided inferior vena cava draining into an azygous vein in the lower thorax, then onto the superior vena cava (Figure 3A). Although this is usually accompanied by another malformation, there are no abnormalities in the shape or number of the spleen, liver, and kidneys. The patient was discharged several days later after an ECG showing appropriate single-chamber AAIR pacing. During the follow-up period, her pacemaker function was adequate. A recent transesophageal echogram revealed the atrial lead is sitting securely at the shallow appendage (Figure 3B).

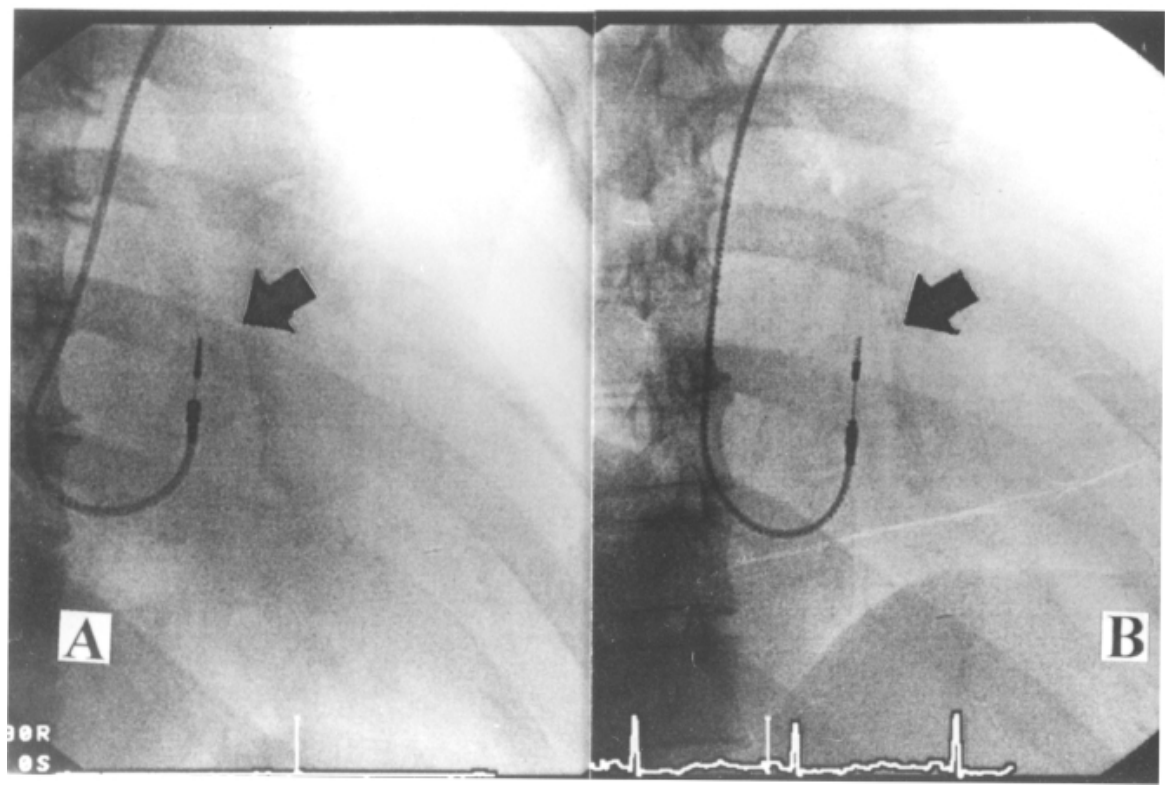

Figure 2 A: A traditional hook-on lead was used initially. B: An endocardial screw-in atrial lead was then later implanted. 
A

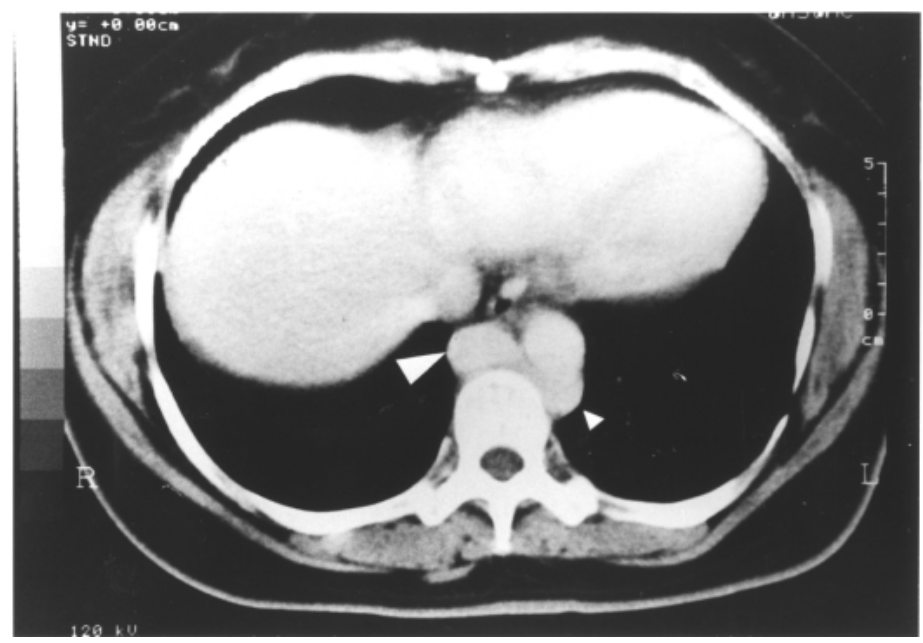

\section{B}

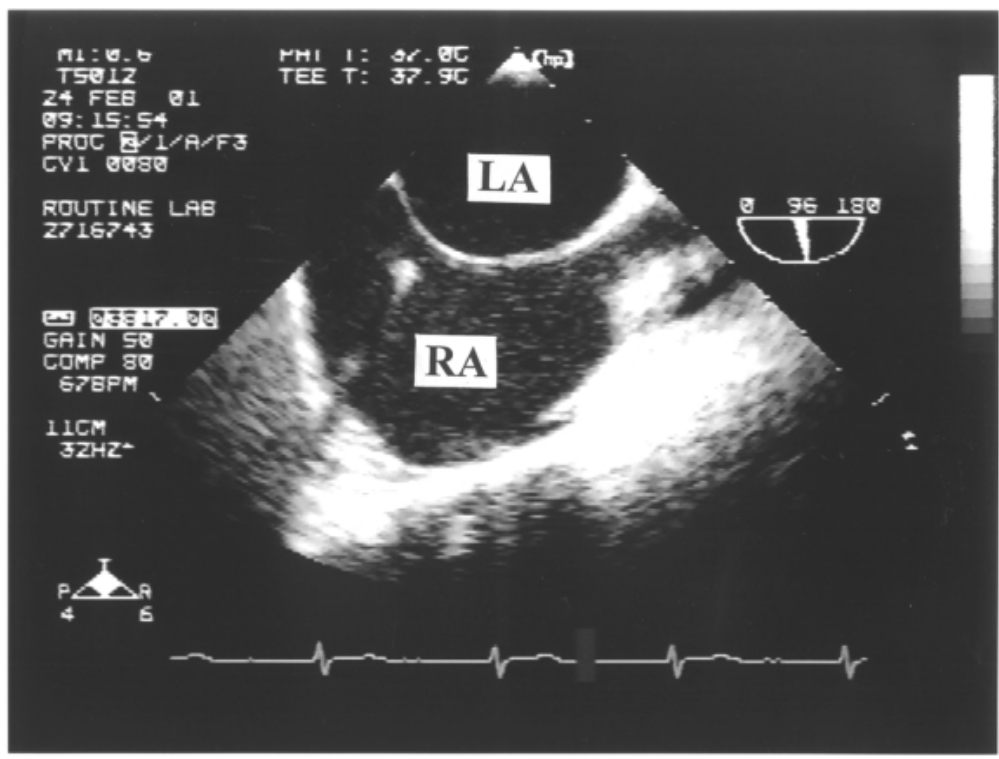

Figure 3 A: Computed tomogram of the chest showing left inferior vena cava (small arrowhead) draining into the enlarged azygous (large arrowhead) in the lower thorax. B: Transesophageal echogram showing the atrial screw-in lead sitting securely at the shallow right atrial appendage (arrow). LA, left atrium; RA, right atrium.

\section{DISCUSSION}

Anomalous inferior vena cava with azygous continuation in individuals without cardiac defects is rarely encountered. An increasing number of recent cases have been detected by anomalous passage of the catheter during right heart 
catheterization. Embryologically, the inferior vena cava originates from the fusion and alteration of components of several different primitive venous pathways. Even though there may be some variants, basically, there are two types, those with azygous continuation and those with hemi-azygous continuation. ${ }^{4}$ Anomalous inferior vena cava with azygous or hemi-azygous continuation is best interpreted as an interruption or failure of the fusion of the hepatic and prerenal segments of the inferior vena cava, combined with the persistence of either the right lumbar azygous vein or the left lumbar hemi-azygous vein. In our case, the patient had a persistent left inferior vena cava with drainage to the enlarged azygous vein and then onto the right superior vena cava.

Anomalous inferior vena cava is known to frequently accompany various rhythm disorders. However, only a few cases have been reported. ${ }^{5)}$ Kakura, et $a l^{6)}$ suggested that the pacemaker cells do not differentiate during the process of development and produce hypoplastic sinus nodes, resulting in sick sinus syndrome. Congenital abnormal systemic venous return, such as a persistent left superior vena cava draining into the coronary sinus, has been implicated in the dislodgment of the pacing electrode tip and resulted in pacemaker failure. ${ }^{7,8)}$ In our case, dislodgment of the hook-on atrial lead occurred repeatedly, most likely due to the enlarged superior vena cava-right atrial connection, which might alleviate the space of atrial appendage for lead lodgment (Figure 1B). Leads can be stabilized in the heart that is always beating. The stability of leads may depend on atrial volume (relative position between the auricle and the superior vena cava), or shape of the atrial appendage. Consequently, we had to use a screw-in atrial lead to overcome the problem.

In conclusion, placement of a traditional hook-on atrial lead can be problematic in such patients. Thus, for better lead fixation, we strongly recommend using a screw-in atrial lead for sick sinus syndrome patients with anomalous inferior vena cava. This disease entity should be added to the indication list of an atrial active fixation lead when it comes to implanting a permanent pacemaker.

\section{REFERENCES}

1. Muelheims GH, J. Mudd G. Anomalous inferior vena cava. Am J Cardiol 1962; 9: 945-52.

2. Hastreiter AR, Rodriguez-Coronel A. Anomalous inferior vena cava with azygos continuation, high (sinus venosus) atrial septal defect and alterations of sinoatrial rhythm. Am J Cardiol 1968; 21: 575-81.

3. van der Horst RL, Gostsman MS. Abnormalities of atrial depolarization in infradiaphragmatic interruption of inferior vena cava. Br Heart J 1972; 34: 295-300.

4. Anderson RC, Adams P, Burke B. Anomalous inferior vena cava with azygous continuation (infrahepatic interruption of the inferior vena cava). The Journal of Pediatrics 1961; 59: 370-83.

5. Fukuzawa J, Haneda, Ishii Y, et al. A case report of isolated levocardia without intracardiac anomalies associated with sick sinus syndrome. Jpn Circ J 1993; 65: 245-90. 
6. Kakura $\mathrm{H}$, Miyahara $\mathrm{K}$, Sohara $\mathrm{H}$, et al. Isolated levocardia associated with the absence of inferior vena cava, lobulated spleen and sick sinus syndrome. Jpn Heart J 1998; 39: 235-41.

7. Kukral, JC. Transvenous pacemaker failure due to anomalous venous return to the heart. Chest 1971; 59: 458.

8. Ho WJ, Kuo CT, Lin KH. Right pneumothorax resulting from an endocardial screw-in atrial lead. Chest 1999; 116: 1133-4. 